\title{
Globe
}

Revue internationale d'études québécoises

\section{Micheline Dumont et Louise Toupin : La pensée féministe au Québec : anthologie 1900-1985. Montréal, Remue-ménage, 2003}

\section{Cristian Micu et Marie-France Raymond-Dufour}

Volume 9, numéro 1, 2006

URI : https://id.erudit.org/iderudit/1000808ar

DOI : https://doi.org/10.7202/1000808ar

Aller au sommaire du numéro

Éditeur(s)

Globe, Revue internationale d'études québécoises

ISSN

1481-5869 (imprimé)

1923-8231 (numérique)

Découvrir la revue

Citer ce compte rendu

Micu, C. \& Raymond-Dufour, M.-F. (2006). Compte rendu de [Micheline Dumont et Louise Toupin : La pensée féministe au Québec : anthologie 1900-1985.

Montréal, Remue-ménage, 2003]. Globe, 9(1), 284-288.

https://doi.org/10.7202/1000808ar d'utilisation que vous pouvez consulter en ligne.

https://apropos.erudit.org/fr/usagers/politique-dutilisation/ 


\section{Micheline Dumont et Louise Toupin \\ La pensée féministe au Québec : anthologie 1900-1985. \\ Montréal, Remue-ménage, 2003.}

L'ouvrage magistral que nous proposent Micheline Dumont et Louise Toupin constitue une revue des différents mouvements et moments de la pensée féministe québécoise depuis 1900 jusqu'en 1985. À travers les 186 textes présentés, il s'agit d'inscrire dans la mémoire collective le développement d'une prise de conscience historique tout en présentant l'apport des femmes dans la culture québécoise. Les deux chercheures, chacune de son côté, avaient déjà publié de nombreux ouvrages sur le rôle, la réalité et l'histoire des femmes ${ }^{6}$. Elles nous proposent ici un voyage dans le temps à travers des textes écrits par les militantes ellesmêmes afin de rendre.compte de la présence d'une tradition de pensée féministe au Québec. Selon elles, la spécificité de la pensée féministe québécoise "s'est constitué à la croisée des influences américaine, anglaise et française, et dans le cadre incontournable de la doctrine sociale de l'Église catholique durant un demi-siècle" (p. 20-21). Par ailleurs, tout en s'inscrivant dans l'évolution socio-idéologique du féminisme occidental, les textes recueillis ici présentent un apport original et novateur à la fois dans son enracinement national et dans la portée de ses ambitions. Il ne s'agit donc pas de juger ces textes à la lumière de nos connaissances actuelles, mais plutôt de discerner la révolte constituant la source même d'un militantisme continuellement renouvelé par les multiples facettes de la condition féminine.

Cet outil pédagogique, utile pour les étudiant(e)s comme pour les chercheur(e)s, est divisé en trois grandes parties traitant chacune une période historique : 1) de 1900 à 1945, définie par "la mobilisation autour de la question des "droits de la femme" "(p. 23) ; 2) de 1945 à 1985, période qui voit évoluer à la fois le féminisme égalitaire et le féminisme radical; 3) de 1969 à 1985, moment où le "nouveau féminisme au Québec "est marqué de façon plus clairement radicale. L'anthologie se

6. Voir notamment Micheline Dumont, Découvrir la mémoire des femmes, Montréal, Remue-ménage, 2001 ; et Louise ToupIN, Les courants de la pensée féministe au Québec, Montréal, Centre de documentation sur l'éducation des adultes et la condition féminine, 1998. 


\section{RECENSIONS}

clôt en 1985 pour une double raison. Cette année marque, à travers des changements politiques, "l'entrée en force du pays dans l'ère néolibérale ( (p. 24) aussi bien qu'une remise en question du féminisme même.

Pour chaque période, les articles sont introduits par un court paragraphe se contentant de situer les extraits dans leur contexte de parution sans que la subjectivité des auteures intervienne. Le choix des extraits est régi par la volonté de présenter des revendications concrètes des féministes et non pas des analyses ayant déjà pris leurs distances par rapport à la praxis. Il s'agit donc d'écrits en situation, relevant du discours sociopolitique, issus de la presse - principalement, mais pas nécessairement - d'allégeance féministe. Ćependant,'si ces textes n'ont pas une visée proprement philosophique, ils manifestent déjà la cohérence d'une pensée en action. Outre certaines illustrations, les manifestations artistiques ont été exclues, affirment les auteures, en raison de leur irréductibilité et du foisonnement d'œuvres à partir des années 1970.

La première partie (185 pages), "Le féminisme et les droits de la femme ", est divisée en quatre champs de revendication : l'éducation, le travail salarié, la situation juridique et les droits sociaux. Les auteures rappellent bien qu'une forte opposition des institutions politiques, religieuses et littéraires par rapport à ce féminisme naissant se fait sentir. Les textes appartenant à cette période ont émergé d'abórd au milieu d'associations protestantes, tel le Canadian Council for Women, dont la publication, The Montreal Local, a débuté dès 1893. La participation des Canadiennes françaises n'était pas interdite par l'association elle-même, mais elle était entravée par l'Église catholique: celle-ci obligeait ses membres à "obtenir des permissions épiscopales pour participer aux activités" (p. 38). Cependant, l'émergence au Québec d'un féminisme catholique n'a pas tardé, marqué par la diffusion du journal français $L e$ Féminisme chrétien. La Fondation nationale Saint-Jean-Baptiste a été établie en 1907. En 1911, les Québécoises ont joint les troupes de la Fédération internationale des ligues féminines catholiques. Une presse féministe catholique s'est ensuite créée, permettant de militer pour le. redressement deș injustices socio-économiques à l'intérieur d'une idéologie qui préférait se tenir en harmonie avec "la doctrine sociale de l'Église : (p. 39) plutôt que d'attaquer de front la question des différences entre hommes et femmes. À l'exception d'Éva Circé-Côté et d'Idola SaintJean, deux femmes de carrière dont les écrits radicaux forment plus du tiers de cette partie, les auteures des autres textes sont des femmes au 
foyer, appartenant à des milieux privilégiés. Ni les mouvements protestants ni les mouvements catholiques n'acceptaient les femmes noires, italiennes ou juives, qui ont dû forger leurs propres groupes en réaction à cette exclusion. N'ayant pas de presse attitrée, ces minorités ne sont pas représentées dans cette anthologie.

Les deuxième et troisième parties, $1945-1985$ et 1969-1985, se chevauchent dans le temps afin d'indiquer à la fois une continuité du féminisme égalitaire et l'avènement d'une nouvelle pensée, plus radicale. Comme l'indique son titre, "Le féminisme comme groupe de pression ", la deuxième partie ( 228 pages) de l'anthologie contredit le lieu commun "qu'après l'obtention du suffrage en 1940 les mouvements féministes [soient] entrés en léthargie " (p. 225). En effet, un nombre impressionnant d'organisations professionnelles féminines se créent des années 1940 jusqu'au début des années 1960 . Des associations de femmes journalistes, universitaires, avocates s'ajoutent ainsi aux deux organisations catholique et protestante, sans allégeance professionnelle particulière, créées au tournant du $\mathrm{xx}^{e}$ siècle. Alors que les auteures mettent en valeur le fait que des revendications "à caractère féministe "sont articulées à ce moment par un grand nombre de femmes de carrière, elles soulignent aussi que l'appellation "féministe " n'est guère utilisée par ces organisations. Le terme n'est pas plus employé par des regroupements "généralistes " comme la Fédération des femmes du Québec et l'Association féminine d'éducation et d'action sociale. Ces dernières représentent néanmoins le début de nouvelles formes de mobilisation féministe et ont par la suite joué un rôle important dans la Révolution tranquille. C'est sous forme de mémoires, et non plus d'articles dans des revues féministes, que se développe une pensée réformiste. Celle-ci, par opposition à la mouvance radicale, est définie par un désir de "réaménager les cadres sociaux " (p. 228). Dans cette deuxième partie, les articles sont présentés selon les mêmes critères de classification que dans la première : l'éducation, le travail salarié, la situation juridique et les droits sociaux.

La troisième partie (262 pages), "Le féminisme comme pensée radicale ", qui va de 1969 à 1985, s'intéresse à une nouvelle tendance du mouvement féministe. Si le féminisme égalitaire était déjà présent dans les milieux politiques et syndicaux dès le milieu des années 1970, les mouvements plus radicaux prennent alors l'avant-scène, et le féminisme devient "une pensée autonome". Contrairement au féminisme réformiste, dont les revendications ne représentaient pas une remise en ques- 


\section{RECENSIONS}

tion complète d'un système d'inégalités, et contrairement au socialisme, qui ne considérait pas "les rapports inégalitaires hommes-femmes * comme * un problème central. (p. 455), le féminisme radical affirme que "l'oppression des femmes est fondamentale et ne peut être réduite à aucune autre oppression " (p. 456). Pour la première fois, on dénonce le patriarcat, tant dans ses structures sociales que dans ses implications dans la sphère privée: "son expression première réside dans la mainmise de la classe des hommes sur le corps des femmes, notamment la mainmise sur la maternité et la sexualité * (p. 456). À travers la critique du patriarcat, de l'hétérosexisme qui le sous-tend et de l'exploitation du travail comme du corps des femmes à l'intérieur du mariage, on signifie que le privé est politique. Ainsi, de nouvelles cibles sont intégrées au combat féministe : on se préoccupe des questions de l'avortement, de la contraception, mais aussi de la réappropriation du corps féminin, de la violence, du viol, de la pornographie, de la sexualité, de l'érotisme et de l'amour. Une vague de solidarité envers des femmes marginalisées (autochtones, immigrantes) ainsi que des considérations nationales se font entendre dans des revues telle Québécoises Deboutte, dont le slogan est "Pas de libération du Québec sans libération des femmes! Pas de libération des femmes sans libération du Québec!"

En terminant, les auteures reviennent sur les apports principaux du féminisme québécois : d'abord, les féministes ont déconstruit l'" argumentation naturaliste" ( $p$. 719) selon laquelle la femme est naturellement, physiquement et psychologiquement inférieure à l'homme. Elles ont également obtenu que l'éducation des filles soit pensée en fonction de "l'humain pur et simple ", et non plus en renforçant les rôles sexuels traditionnels. Ensuite, elles se sont battues pour que la femme célibataire soit considérée comme un être à part entière qui a sa place dans le monde, sans avoir à être sous la garde d'un homme pour exister pleinement dans la société. Elles se sont donc appliquées à abolir le double standard régissant les inégalités hommes-femmes. De plus, les féministes ont contribué à une responsabilisation des femmes quant à leurs droits, à leur destin et à leurs devoirs. Il ne s'agit pas seulement de s'insurger contre un système opprimant, mais bien de "cesser d'être complices d'une discrimination" (p. 720). Finalement, les féministes radicales auraient contribué à penser l'oppression patriarcale en tant que système à décortiquer, puis à déconstruire collectivement, et non plus seulement à travers des actes d'émancipation individuels. 
Il est évident que cette anthologie représente la somme d'un énorme travail effectué par les deux chercheures que sont Dumont et Toupin. Toutefois, l'occultation de textes plus littéraires, comme la prose de Nicole Brossard, ou de pièces de théâtre, telle Les fées ont soif de Denise Boucher, peut étonner. En effet, ces manifestations culturelles ont tout autant contribué à l'essor de la pensée féministe et à son développement social que les textes des militantes des autres disciplines. En outre, si le nombre d'extraits est impressionnant, il aurait été pertinent d'en présenter certains dans leur totalité afin de faire parler les textes dans leur plénitude rhétorique. Finalement, une question persiste : pourquoi ne pas avoir considéré les nouveaux discours féministes qui circulent depuis 1985 jusqu'en 2000, alors que certaines féministes radicales se font encore entendre et qu'une nouvelle génération de féministes s'applique à dresser un portrait actualisé de la condition féminine? Cela étant dit, Micheline Dumont et Louise Toupin, avec leur Anthologie de la pensée féministe au Québec, ont accompli une tâche inégalée dans le domaine, et leur ouvrage fera certainement le bonheur des chercheur(e)s et historien(ne)s des idées au Québec.

\author{
Cristian Micu et \\ Marie-France Raymond-Dufour \\ Université de Toronto
}

\title{
Élisabeth Gallat-Morin et Jean-Pierre Pinson
}

La vie musicale en Nouvelle-France.

Sillery, Septentrion, 2003.

À force de vivre dans un monde sursaturé de musique, on en viendrait presque à oublier qu'il n'en a pas toujours été ainsi. On ne s'étonne plus de tant de choix, que ce soit en téléchargeant une chanson sur Internet, en furetant dans le bac d'un disquaire où se retrouvent soldées les vedettes d'hier, ou même en s'impatientant de subir dans le métro à la fois la musique de haut-parleurs déficients et la complainte du musicien ambulant - quand ce n'est pas le baladeur du voisin! Parmi les nombreux attraits que comporte la lecture de La vie musicale en Nouvelle-France, qu'il nous soit permis de mentionner une rafraîchissante remise en perspective, qui nous amène à méditer sur le lien 